\title{
Analisis Faktor yang Mempengaruhi Keputusan Pembelian Produk Teh Jawa pada Masyarakat Kabupaten Pekalongan
}

\author{
Analysis of Factors Affecting Purchase Decisions for Javanese Tea Products in \\ Pekalongan Regency Society
}

\author{
Aqbila Fadhlia ${ }^{1}$, Sri Wahyuningsih ${ }^{2}$, Hendri Wibowo ${ }^{3}$, Aniya Widiyani ${ }^{4}$ \\ ${ }^{1,2,3,4}$ Program Studi Agribisnis Fakultas Pertanian \\ Universitas Wahid Hasyim Semarang
}

\begin{tabular}{l} 
ARTICLE INFO \\
\hline Article history: \\
DOI: \\
10.30595/pspfs.v2i.208
\end{tabular}

\begin{abstract}
Purchasing decisions is a consumer decision-making process of purchasing a product that combines knowledge to select two or more available products. This study aims to analyze the factors that influence consumers in the decision to purchase Java Tea products, a case study on the people of Pekalongan Regency. The data used is primary data and secondary data. The basic method used in this study is descriptive analysis. Determination of location samples using purposive sampling and determination of respondent samples using accidental sampling. The sample was studied by 100 respondents. The number of variables studied 9 variables that can be analyzed further. The results showed that the results of 9 variables analyzed by regression analysis method of 7 significant variables with a confidence level of $95 \%(\alpha 0.05)$ include free variables consumer habits, family/friends as a reference, income level, lifestyle, product price, selfconfidence and self-encouragement. The result of the analysis of the type of Javanese tea that consumers like the most is the type of brewed tea. The result of the analysis of flavor variants that consumers like the most is Jasmine Tea. The results of the analysis of characteristics that affect consumers include flavor aroma, product variants, flavor variants, product availability, affordable prices, product packaging, promotional media, expired information, halal certification and outlet branches.
\end{abstract}

This work is licensed under a Creative Commons Attribution 4.0 International License.

Keywords:

Purchasing Decisions, Types, Variants, Characteristics

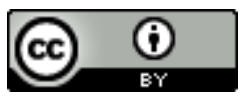

Corresponding Author:

Aqbila Fadhlia

Program Studi Agribisnis Fakultas Pertanian

Universitas Wahid Hasyim Semarang

Email: aqbila@gmail.com

\section{PENDAHULUAN}

Manusia merupakan makhluk sosial yang memiliki berbagai macam kebutuhan dalam hidupnya. Kebutuhan hidup manusia yang paling penting adalah kebutuhan akan makanan dan minuman, karena termasuk kebutuhan dasar manusia yang harus terpenuhi sebagai sumber energi untuk tubuh manusia. Terutama dalam kebutuhan mengonsumsi teh, teh merupakan salah satu minuman yang diminati oleh masyarakat. Banyak perusahan di Indonesia yang memproduksi teh, semakin banyaknya persaingan bisnis dalam memasarkan produk teh maka harus ada strategi dari perusahaan masing-masing dalam menarik minat konsumen. 
Perkembangan dunia bisnis yang dibarengi dengan perubahan pola pikir konsumen yang dinamis mempengaruhi keputusan konsumen dalam membeli produk. Keberadaaan konsumen memberikan pengaruh terhadap tujuan akhir pencapaian perusahaan, yaitu memperoleh keuntungan atau laba melalui pembelian produk disertai dengan kepuasan konsumen yang akan berakhir dengan terjadinya pembelian secara terusmenerus. Karena hal inilah yang menyebabkan perusahaan harus memahami faktor penyebab terjadinya keputusan konsumen dalam melakukan pembelian suatu produk agar konsumen membeli barang dan jasa perusahaan pada saat mereka membutuhkan (Sari, 2013). Teh sebagai komoditas penyumbang devisa negara melalui non-migas menunjukkan perkembangan produksi yang cukup baik. Secara keseluruhan pertumbuhan produksi teh olahan meningkat rata-rata $6,78 \%$ setiap tahunnya. Semakin meningkatnya permintaan terhadap komoditas teh olahan menyebabkan perusahan makanan dan minuman semakin tertantang untuk bersaing menciptakan produk baru berbasis daun teh (Wiedjarnarko et al., 2015). Teh merupakan salah satu produk minuman yang banyak digemari oleh masyarakat Indonesia. Minuman ini banyak dikonsumsi karena cita rasa dan aromanya yang khas, memberikan kesegaran, dan memiliki manfaat yang baik untuk kesehatan (Dewi \& Solikah, 2018).

Menurut data dari Dinas Pertanian dan Perkebunan Provinsi Jawa Tengah, 2018 wilayah Kabupaten Pekalongan memproduksi teh dengan skala besar yaitu 945,37/ton. Masyarakat Kabupaten Pekalongan juga mempunyai kebiasaan mengonsumsi teh sebagai kebutuhan sehari-hari. Melihat skala jumlah pertumbuhan masyarakat Kabupaten Pekalongan yang begitu cukup besar bisa dijadikan sebagai bahan penelitian keputusan pembelian produk teh. Banyaknya perusahaan teh yang ada di daerah Pekalongan dan Batang membuat daya saing pemasaran produk teh semakin meningkat. Salah satunya terdapat produk teh yang cukup terkenal di Teh Jawa merupakan produk teh yang diproduksi oleh PT. Sari Melati Sejatera yang bertempat di Kota Pekalongan. Produk Teh Jawa yang diproduksi ada tiga macam yaitu teh seduh, teh celup dan teh cup (teh kemasan). Ketiga macam Teh Jawa tersebut memiliki daya tarik masing-masing sehingga selalu menarik daya minat masyarakat untuk mengonsumsinya. Berdasarkan uraian yang sudah dijelaskan diatas maka perumusan permasalahan yang akan diangkat dalam penelitian ini : (1) Faktor-faktor apa saja yang mempengaruhi konsumen dalam keputusan pembelian produk Teh Jawa di Kabupaten Pekalongan? (2) Jenis Teh Jawa yang paling disukai konsumen? (3) Jenis varian rasa yang paling disukai konsumen? (4) Karakteristik produk apa saja yang mempengaruhi konsumen memilih Teh Jawa?. Tujuan dari penelitian ini : untuk mengetahui faktor-faktor yang mempengaruhi konsumen dalam keputusan pembelian produk Teh Jawa di Kabupaten Pekalongan, untuk mengetahui jenis Teh Jawa yang paling disukai konsumen, untuk mengetahui varian rasa yang paling disukai konsumen, dan untuk mengetahui karakteristik produk apa saja yang mempengaruhi konsumen memilih Teh Jawa.

\section{METODE PENELITIAN}

Metode penelitian yang digunakan dalam peneltian ini adalah metode deskriptif. Penelitian dilaksanakan pada Maret 2021. Daerah penelitian ditetapkan di Kabupaten Pekalongan meliputi toko kelontong, minimarket, dan supermarket. Dalam pelaksanaan penelitian ini menggunakan metode pelaksanaan studi kasus (Case Studies). Pengambilan sampel lokasi dilakukan dengan metode purposive sampling. Sedangkan teknik pengambilan sampel menggunakan accidental sampling. Data yang digunakan meliputi data primer dan sekunder. Data yang telah terkumpul selanjutnya dianalisa dengan cara sebagai berikut :

a. Analisis deskriptif ini digunakan untuk melihat karakteristik konsumen produk Teh Jawa di Kabupaten Pekalongan dan selanjutnya ditabulasikan dan dipersentasekan data yang diperoleh.

b. Analisis regresi linier adalah untuk mengukur intensitas hubungan antara dua variabel atau lebih dan memuat prediksi/perkiraan nilai Y dan nilai X. bentuk umum persamaan regresi linier berganda yang mencakup dua atau lebih variabel (Pratomo \& Astuti, 2014). Data yang dibutuhkan adalah indikator kebiasaan konsumen, keluarga/teman sebagai referensi, tingkat penghasilan, gaya hidup, harga produk, harga produk lain, ketersediaan produk, keyakinan diri dan dorongan diri. Adapun rumus yang digunakan sebagai berikut:

$$
\mathrm{Y}=\mathrm{b}_{0}+\mathrm{b}_{1} \mathrm{X}_{1}+\mathrm{b}_{2} \mathrm{X}_{2}+\mathrm{b}_{3} \mathrm{X}_{3}+\ldots+\mathrm{b}_{\mathrm{n}} \mathrm{X}_{\mathrm{n}}
$$

\section{HASIL DAN PEMBAHASAN}

Responden pada penelitian ini adalah konsumen akhir produk Teh Jawa di Kabupaten Pekalongan dengan jumlah responden yang dillibatkan dalam penelitian ini sebanyak 100 konsumen. Data karakteristik responden produk Teh Jawa dapat dilihat pada Tabel 1.

Berdasarkan Tabel 1. Dapat diketahui bahwa konsumen produk Teh Jawa didominasi dengan konsumen berjenis kelamin perempuan. Perempuan dalam hal ini lebih banyak melakukan pembelian produk Teh Jawa dibandingkan dengan konsumen berjenis kelamin laki - laki. Hal ini sejalan dengan pendapat (Eliza et al., 2011) yang menyatakan bahwa umumnya perempuan berperan dalam hal pengambilan keputusan pembelian serta melakukan berbagai kegiatan pembelanjaan dalam pemenuhan kebutuhan dan konsumsi rumah tangga. Tingkat pendidikan konsumen paling banyak adalah setingkat SMA sebnayak 52\%. Konsumen yang memiliki pendidikan yang tinggi memiliki pendidikan yang lebih baik akan terhadap infomasi dan tentunya sangat

Proceedings homepage: https://conferenceproceedings.ump.ac.id/index.php/pspfs/issue/view/9 
selektif dalam pemilihan produk yang akan dibeli, tidak asal - asalan dalam memilih produk. Sementara berdasarkan usia, konsumen produk Teh Jawa rata - rata berumur 41 - 50 tahun. Variasi usia responden merupakan hal penting bagi para pemasar dikarenakan usia dapat mempengaruhi selera konsumen terhadap produk yang dibeli.

Tabel 1. Karakteristik Responden Berdasarkan Jenis Kelamin, Usia, Tingkat Pendidikan, Status Pekerjaan,Penghasilan Responden di Kabupaten Pekalongan.

\begin{tabular}{lllcc}
\hline \multirow{2}{*}{ No. Karakteristik } & Keterangan & Jumlah & $\begin{array}{c}\text { Persentase } \\
(\boldsymbol{\%})\end{array}$ \\
\hline 1 & Jenis kelamin & Laki - laki & 43 & $43 \%$ \\
& & Perempuan & 57 & $57 \%$ \\
\hline 2 & Usia & $21-30$ & 5 & $5 \%$ \\
& & $31-40$ & 22 & $22 \%$ \\
& & $41-50$ & 23 & $23 \%$ \\
& & $51-60$ & 32 & $32 \%$ \\
& & $>60$ & 13 & $13 \%$ \\
& & SD & 5 & $5 \%$ \\
\hline & Tingkat Pendidikan & SMP & 6 & $6 \%$ \\
& & SMA/SMK & 11 & $11 \%$ \\
& & Perguruan Tinggi & 52 & $52 \%$ \\
& & Pedagang & 31 & $31 \%$ \\
\hline 4 & Mata Pencaharian & Wiraswasta & 8 & $8 \%$ \\
& & Buruh & 11 & $11 \%$ \\
& & Ibu Rumah Tangga & 21 & $21 \%$ \\
& & Pegawai/karyawan & 25 & $25 \%$ \\
& & Guru & 14 & $14 \%$ \\
& & Mahasiswa/Pelajar & 3 & $3 \%$ \\
& & Lainnya & 11 & $11 \%$
\end{tabular}

Sumber : Analisis Data Primer Diolah, 2021

Pekerjaan konsumen terbanyak adalah sebagai ibu rumah tangga yaitu sebanyak $25 \%$. Status pekerjaan penduduk suatu wilayah dipengaruhi oleh beberapa hal diantaranya meliputi sumber daya yang tersedia, kondisi geografis, kondisi sosial ekonomi serta tingkat pendidikan. Penghasilan responden diketahui bahwa rata - rata pendapatan per bulan yaitu $500.000-1.000 .000$ dengan persentase 38\%. Pendapatan responden merupakan faktor yang berpengaruh pada perilaku konsumsi dalam suatu rumah tangga. Jika besar pendapatan seseorang maka semakin besar juga kemampuan dalam membeli kebutuhan, begitupun sebaliknya.

\section{Analisis Faktor - Faktor Yang Mempengaruhi Keputusan Pembelian Produk Teh Jawa}

Hasil analisis regresi berganda pada Tabel 2. Menunjukan bahwa faktor yang mempengaruhi keputusan pembelian produk Teh Jawa dapat diformulasikan dalam model sebagai berikut:

$$
\begin{aligned}
\hat{Y}= & 1.343+0,253 X_{1}+0,459 X_{2}+0,421 X_{3}+0,525 X_{4}-0,006 X_{5}+0,449 X_{6}-0,359 X_{7}+0,525 X_{8}+ \\
& 0,476 X_{9}+\mu
\end{aligned}
$$

$\hat{Y}=$ Keputusan Pembelian

$\mathrm{X}_{1}$ : Kebiasaan konsumen

$\mathrm{X}_{2}$ : Keluarga/teman sebagai referensi

$\mathrm{X}_{3}$ : Tingkat penghasilan konsumen

$\mathrm{X}_{4}$ : Gaya hidup

$$
\begin{aligned}
& \mathrm{X}_{5}: \text { Harga produk } \\
& \mathrm{X}_{6}: \text { Harga produk lain } \\
& \mathrm{X}_{7}: \text { Ketersedian produk } \\
& \mathrm{X}_{8}: \text { Keyakinan diri sendiri } \\
& \mathrm{X}_{9}: \text { Dorongan diri }
\end{aligned}
$$

Adapun hasil analisis regresi berganda faktor yang mempengaruhi keputusan pembelian produk Teh Jawa secara rinci pada Tabel 2. 
Tabel 2. Hasil Analisis Regresi Faktor - Faktor Yang Mempengaruhi Konsumen Dalam Keputusan Pembelian Produk Teh Jawa

\begin{tabular}{lccc}
\hline Variabel & Koefisien Regresi & t-Hitung & Prob. Signifikan \\
\hline Konstanta & 1.343 & 1.558 & .001 \\
Kebiasaan Konsumen & .253 & 3.288 & $.001^{*}$ \\
Keluarga Sebagai Referensi & .459 & 6.885 & $.021^{*}$ \\
Tingkat Penghasilan & .421 & 6.424 & $.000^{*}$ \\
Gaya Hidup & .525 & 8.979 & $.000^{*}$ \\
Harga Produk & -.006 & 5.683 & $.008^{*}$ \\
Harga Produk Lain & .449 & -6.514 & .342 \\
Ketersediaan Produk & -.359 & -3.926 & .795 \\
Keyakinan Diri & .525 & 3.926 & $.009^{*}$ \\
Dorongan Diri & .476 & 8.973 & $.007^{*}$ \\
Koefisien & $.823^{\mathrm{a}}$ & & \\
Determinasi (R ${ }^{2}$ ) & .677 & & 0.000 \\
Adjusted R Square & .645 & & \\
F Hitung & 20.981 & Sig & \\
F Tabel 5\% & 1.99 & & \\
T Tabel 5\% & 1.986 & & \\
Durbin Watson & 1.662 & & \\
\hline Keterangan: & & & \\
\hline
\end{tabular}

Keterangan :

*Signifikan pada tingkat kepercayaan $95 \%(\alpha 0,05)$

Sumber : Analisis Data Primer diolah, 2021

Berdasarkan hasil olah data dengan IBM SPSS Statistic 24 menyatakan bahwa semua variabel bebas dari uji asumsi klasik yang meliputi : uji normalitas, uji multikolonieritas, dan uji heteroskedastisitas sehingga model regresi linier ini layak digunakan dalam penelitian. Berdasarkan data hasil olah regresi pada Tabel 2. menyatakan bahwa nilai koefisien determinasi Adjusted R Square sebesar 0,645. Hal ini menunjukan proporsi pengaruh variabel bebas (kebiasaan konsumen, keluarga/teman sebagai referensi, tingkat penghasilan, gaya hidup, harga produk, harga produk lain, ketersediaan produk, keyakinan diri dan dorongan diri) terhadap variabel terikat (keputusan pembelian) sebesar 64,5\% sedangkan 35,5\% dipengaruhi oleh variabel lain yang tidak terdapat pada model regresi linear dalam penelitian ini. Berdasarkan uji F statistik yang telah dilakukan, menunjukan model regresi yang diestimasi layak dan variabel bebas secara keseluruhan bersama - sama berpengaruh secara signifikan terhadap variabel terikat berupa keputusan pembelian produk Teh Jawa.

Uji t statistik digunakan untuk menguji seberapa jauh pengaruh satu variabel bebas secara individual dalam memengaruhi variabel terikat. Berdasarkan hasil olah regresi dapat diketahui bahwa variabel bebas yang terdiri dari (kebiasaan konsumen, keluarga/teman sebagai referensi, tingkat penghasilan, gaya hidup, harga produk, keyakinan diri dan dorongan diri) secara nyata (signifikan) terhadap variabel terikat (keputusan pembelian produk Teh Jawa), sedangkan variabel bebas (harga produk lain, ketersediaan produk) tidak berpengaruh nyata terhadap variabel terikat. Variabel bebas yang berpengaruh secara nyata (signifikan) berada pada tingkat kepercayaan 95\%. Sejalan dengan penelitian (Jayakusumah, 2011) yang menyatakan bahwa faktor kebiasaan konsumen, keluarga/teman sebagai referensi, keyakinan diri, dorongan diri merupakan faktor - faktor yang mempengaruhi keputusan pembelian suatu produk. Menurut (Edy et al., 2020) dalam penelitiannya menyatakan bahwa faktor tingkat pendapatan dan gaya hidup berpengaruh nyata terhadap proses keputusan pembelian.

\section{Hasil Analisis Jenis Teh Jawa Yang Paling Disukai Konsumen}

Tabel 3. Hasil Analisis Jenis Produk Teh Jawa

\begin{tabular}{llll}
\hline No & Jenis Teh & Responden & Persentase (\%) \\
\hline 1 & Teh Seduh & 52 & $52 \%$ \\
2 & Teh Celup & 28 & $28 \%$ \\
3 & Teh Cup/Kemasan & 20 & $20 \%$ \\
\hline & Total & $\mathbf{1 0 0}$ & $\mathbf{1 0 0}$ \\
\hline
\end{tabular}

Sumber : Analisis Data Primer, 2021

Berdasarkan hasil analisis tabulasi pada Tabel 3. menunjukan bahwa jenis Teh Seduh yang paling sering dibeli konsumen yaitu sebanyak 52\%. Kriteria untuk pengukuran preferensi sebagai berikut: Rendah : $0-26 \%$, Sedang : $26-50 \%$, Tinggi : $51-75 \%$, Sanggat Tinggi : 76 - $100 \%$ (Kamelta, 2013). 
Kriteria untuk pengukuran preferensi konsumen terhadap produk Teh Jawa dengan jenis teh seduh tergolong dengan kriteria tinggi ( $51-75 \%$ ). Teh seduh banyak disukai oleh konsumen karena bentuk teh siap seduh yang berbentuk potongan daun yang lebih kasar dibandingkan dengan serbuk teh yang terdapat pada teh kantong (celup). Teh seduh memiliki aroma dan rasa yang lebih tajam dibandingkan teh celup.

\section{Hasil Analisis Varian Rasa Yang Paling Disukai Konsumen}

Tabel 4. Hasil Analisis Berdasarkan Varian Rasa Teh Jawa

\begin{tabular}{llcc}
\hline No & Varian Rasa & Responden & Persentase (\%) \\
\hline 1 & Jasmine Tea & 42 & $42 \%$ \\
2 & Green Tea & 27 & $27 \%$ \\
3 & Vanilla Tea & 15 & $15 \%$ \\
4 & Black Tea & 16 & $16 \%$ \\
\hline & Total & $\mathbf{1 0 0}$ & $\mathbf{1 0 0}$ \\
\hline
\end{tabular}

Sumber : Analisis Data Primer, 2021

Berdasarkan hasil analisis pada Tabel 4.19 dapat diketahui bahwa varian rasa Jasmine Tea sangat digemari atau disukai oleh konsumen, dengan tingkat persentase $42 \%$ atau sebanyak 42 responden yang menyukai varian rasa Jasmine Tea. Kriteria untuk pengukuran preferensi konsumen terhadap produk Teh Jawa dengan varian rasa Jasmine Tea tergolong dalam kriteria sedang (21 - 50\%). JasmineTea dikenal sebagai salah satu jenis teh yang terpopuler, bisa dilihat dari sekian banyak produk teh yang diproduksi salah satu varian rasa yang dikeluarkan terdapat rasa Jasmine Tea. Teh dengan aroma bunga melati ini sangat digemari karena rasanya yang ringan dan aromanya yang harum.

\section{Hasil Analisis Karakteristik Teh Jawa Yang Mempengaruhi Konsumen}

Tabel 5. Atribut dan Indikator Preferensi Teh Jawa

\begin{tabular}{|c|c|c|c|c|c|}
\hline No. & Atribut & Total Skor & $\begin{array}{c}\text { Jumlah } \\
\text { Pertanyaan }\end{array}$ & $\mathbf{Q}=\mathbf{P} / \mathbf{E}$ & \% Skor \\
\hline 1 & Aroma Rasa & 429 & 1 & 0,10 & $10 \%$ \\
\hline 2 & Varian Produk & 420 & 1 & 0,10 & $10 \%$ \\
\hline 3 & Varian Rasa & 408 & 1 & 0,09 & $10 \%$ \\
\hline 4 & $\begin{array}{l}\text { Ketersediaan produk di } \\
\text { pasaran }\end{array}$ & 405 & 1 & 0,09 & $10 \%$ \\
\hline 5 & Harga Terjangkau & 409 & 1 & 0,10 & $10 \%$ \\
\hline 6 & Kemasan produk & 329 & 1 & 0,08 & $10 \%$ \\
\hline 7 & Media promosi & 378 & 1 & 0,08 & $10 \%$ \\
\hline 8 & Informasi kadaluarsa & 404 & 1 & 0,09 & $10 \%$ \\
\hline 9 & Sertifikasi halal & 423 & 1 & 0,10 & $10 \%$ \\
\hline 10 & Cabang Outlet & 419 & 1 & 0,10 & $10 \%$ \\
\hline
\end{tabular}

Sumber : Hasil Data Primer, 2021

Berdasarkan Tabel 5 terlihat hasil rekapitulasi yang menunjukan bahwa dimensi Perceived Quality memiliki rata-rata skor 0,93 , dan masing - masing memiliki persentase skor yaitu 10\%. Dapat dilihat dari jumlah skor bahwa aroma rasa memiliki nilai paling tertinggi yaitu 429. Sedangkan nilai terendah terdapat pada kemasan produk. Ini berarti bahwa aroma rasa pada Teh Jawa memiliki rasa yang khas pada produk tersebut. Konsumen yang memperoleh kepuasan cenderung melakukan pembelian ulang produk yang sama. Salah satu faktor penting yang dapat menghasilkan kepuasan konsumen adalah kualitas. Kualitas yang baik dari suatu produk akan mempengaruhi konsumen dalam menentukan pilihannya untuk menggunakan produk tersebut sehingga memudahkan konsumen dalam pengambilan keputusan pembelian. Suatu produk dikatakan berkualitas apabila produk tersebut dapat memenuhi keinginan dan kebutuhan sesuai dengan yang diharapkan atau melebihi apa yang konsumen harapkan (Kurniawati et al., 2017).

\section{KESIMPULAN}

Hasil penelitian dapat disimpulkan berdasarkan hasil analisis regresi linier berganda diperoleh hasil Adjusted R Square sebesar 64,5 \%, F hitung 20,981. Sedangkan faktor - faktor yang mempengaruhi keputusan pembelian produk Teh Jawa meliputi kebiasaan konsumen, keluarga/teman sebagai referensi, tingkat 
penghasilan, gaya hidup, harga produk, keyakinan diri, dan dorongan diri sendiri. Jenis Teh Jawa yang paling disukai konsumen atau menjadi pilihan konsumen di Kabupaten Pekalongan adalah jenis teh seduh dengan jumlah 52 atau 52\%. Varian rasa Teh Jawa yang paling disukai konsumen di Kabupaten Pekalongan adalah rasa Jasmine Tea dengan jumlah 42 atau 42\%. Karakteristik produk Teh Jawa yang paling mempengaruhi konsumen adalah aroma rasa karena pada Teh Jawa sendiri mempunyai rasa yang khas yang menunjukan kualitas dari teh tersebut.

\section{UCAPAN TERIMA KASIH}

Pada kesempatan ini penulis mengucapkan terima kasih yang sebesar-besarnya kepada semua pihak yang secara langsung maupun tidak langsung telah membantu dalam penyusunan penelitian ini, kepada:

1. H. Lutfi Aris Sasongko, S.TP., M.Si selaku Dekan Fakultas Pertanian Universitas Wahid Hasyim Semarang.

2. Shofia Nur Awami, SP., M.Sc selaku Keprodi Agribisnis Fakultas Pertanian Universitas Wahid Hasyim Semarang.

3. Sri Wahyuningsih, S.P., M.P, Hendri Wibowo, S.P., M.P, dan Aniya Widiyani, S.TP., M.P. selaku dosen pembimbing dan penguji yang senantiasa memberikan pengarahan dan membimbing dengan penuh kesabaran.

4. Seluruh responden dalam penelitian Keputusan Pembelian Konsumen Pada Produk Teh Jawa yang telah memberikan ilmu, informasi dan meluangkan waktu dalam pengumpulan data penelitian ini.

\section{DAFTAR PUSTAKA}

Badan Pusat Statistik. Tanaman Perkebunan Produksi Teh Tahun 2018. Dinas Pertanian dan Perkebunan Jawa Tengah.

Dewi, T. R., \& Solikah, U. N. (2018). Model Tipe Perilaku Konsumen Dalam Membeli Teh Di Kabupaten Sukoharjo. Journal of Chemical Information and Modeling, 53(9), 1689- 1699.

Edy, I. T., Mauladi, K. F., \& Efendi, Y. (2020). Analisis Faktor Pendapatan Dan Gaya Hidup Terhadap Keputusan Pembelian Barang Elektronik Pada Ud. Dewi Sri Elektronik Lamongan. Universitas Islam Lamongan. 19(1), 124-129.

Eliza, Sayamar, E., \& Kaswita, C. (2011). Analisis Faktor-Faktor Yang Mempengaruhi Konsumen Dalam Pengambilan Keputusan Pembelian Buah Di Pasar Arengka (Pasar Tradisional) Dan Giant Hypermarket (Pasar Modern) Di Kecamatan Tampan Kota Pekanbaru. Indonesia. Journal of Agricultural Economics (IJAE), 2(1), 15-34.

Jayakusumah, H. (2011). Analisis Faktor-Faktor Yang Mempengaruhi Konsumen Dalam Keputusan Pembelian Teh Celup Sariwangi (Studi Kasus Pada Masyarakat Kota Bekasi). Institut Pertanian Bogor. January, 30-33.

Kamelta, E. (2013). Pemanfaatan Internet Oleh Mahasiswa Teknik Sipil Fakultas Teknik Universitas Negeri Padang. Cived, 1, 142-146.

Kurniawati, D. I., Sampurno, \& Mx, D. (2017). Brand Image, Quality Product, Price Marcks Venus Powder on Purchase Decision it's Impact Customer Satisfaction. Journal Economic. 19(3), 314-331.

Pratomo, D. S., \& Astuti, E. Z. (2014). Analisis Regresi dan Korelasi Antara Pengunjung dan Pembeli Teradap Nominal Pembelian di Indomaret Kedungmundu Semarang Dengan Metode Kuadrat Terkecil. Ilmu Komputer, 1. Universitas Dian Nuswantoro. Semarang.

Sari, Y. D. (2013). Analisis Faktor-Faktor Yang Mempengaruhi Keputusan Konsumen Dalam Membeli Produk Industri Garment. Journal of Chemical Information and Modeling, 53(9), 1689-1699.

Wiedjarnarko, S., Fauzi, A. M., \& Rusli, M. S. (2015). Strategi Distribusi Produk Teh Siap Saji. Jurnal Manajemen Dan Agribisnis, 12(1), 68-77. 